\title{
Inclusion by Live Streaming? - Contested Meanings of Well-being: Movement and Non-movement of Space, Place and Body
}

\author{
Tarja Rautiainen-Keskustalo* and Sanna Raudaskoski \\ ${ }^{a}$ Faculty of Information Technology and Communication Sciences, University of Tampere, \\ Tampere, Finland; ${ }^{\mathrm{b}}$ Faculty of Social Sciences, University of Tampere, Tampere, Finland
}

Keywords: Mobility of institutions; the arts; live-streaming; inclusion; governmobility; kinaesthetics; mobile methods.

\begin{abstract}
:
The article explores how the ideological discourses and practical actions that aim to increase wellbeing by means of art are possible to understand from the point of view of different kinds of mobilities and immobilities. An empirical case of a concert series live streamed to seniors and

prison inmates by a concert hall is examined. The concerts aimed to enhance cultural inclusion, but in practice, live streaming highlighted the complexity of the network, where social spaces, places and bodily resources of the individuals were negotiated through movement and

non-movement.
\end{abstract}

\section{Introduction}

During the last ten years, the focus on the impact of the arts on well-being has generated an extensive number of national and small-scale projects around the globe. The topic has been a buzzword, both in national arts policies and public discussions. Although the complexity of the concept of well-being is widely recognised, there is a common assumption that the arts, in a trouble-free way, 'improve' the quality of life of individuals (i.e. the arts produce easily measured positive outcomes). Thus, many research projects in this field fall into the category of health sciences, emphasising 'hard knowledge' or evidence-based results (c.f. Clift 2012; Daykin et al. 2017). One reason for this is the modern Western notion of the arts (i.e. art for art's sake) that often separates and encapsulates the arts from other fields of society, such as care. It is precisely this separation that seems to accentuate the idea of the arts as 'medicine', which, in turn, obscures the idea, what is the socio-spatial terrain where 'the arts as wellbeing' projects and services are conducted (1).

This research setting was the starting point for the project, where we (Rautiainen-Keskustalo et al. 2014) studied the effects on the well-being of a live-streamed concert series produced by a Finnish concert hall and transmitted to individuals who had no way of participating in cultural activities. The individuals in this case were people living in two elderly care homes and one prison. With 'live-streaming,' we refer to the delivery of an ongoing concert over the internet to 'remote' audiences who were watching the concerts on a large screen that was placed in a suitable space, such as a canteen or lounge.

The streamed concert series differed from other 'arts as well-being' projects in that it was not introduced as a special project for 'excluded people.' Rather, the principle goal was to make an existing practice more inclusive and enhance well-being as a result. Staff members of the elderly homes and prison saw the pilot project as necessary, because a lack of social cohesion and meaningful activities for residents were common problems for them. The choice proved to be very significant because the starting point was to maintain the traditional role of the audience, i.e. 
listener, viewer, that is to say concerts were not formulated as 'participatory' where the audience is engaged, in a one way or another, with the creative process (e.g. Clements 2011). For the organizers, this guaranteed the inclusiveness of the project as the same service was made available for both 'normal' and 'excluded' people. The argument indicated how the spatial formation of the terrain was understood among the parties: it was the concert practise, which was seen to 'move' between the places and the institutions, while the static position of the institutions was considered to stay. In other words, the concerts were seen as products that were exported from one institution to another. When studying the concerts (Rautiainen-Keskustalo et al. 2014), the complexity of the configuration was apparent from the beginning, and issues concerning movement and stasis seemed to be especially crucial. By definition, live-streaming highlighted the constitutive role of movement in this cultural project. Together with musical material, which moved over the spaces, the institutions opened up to 'flowing' and 'moving' when live-streaming established a connection between them.

This observation presents a starting point for this article, where we will analyse live-streamed concerts through the lens of the new mobilities paradigm (Urry 2000, 2003, 2007; Hannam, Sheller, and Urry 2006; Sheller and Urry 2016), focusing on how concerts constitute a complex assembly of movements and moorings (Urry 2000; Sheller and Urry 2016). Conducting a 'movement-driven' (Büscher, Urry, and Witchger 2011) analysis means that we focus on both social and material worlds. Firstly, we are interested in how the concerts implied movement and change in connections and social relationships. Because the study of these aspects cannot be separated from different kind of materialities, including technology, constituting movement, and also, non-movement (ibid. 3) we are, secondly, interested in how live streaming generated virtual flux

(Urry 2000, 70-71) in material terms, i.e. what particular kind of material agency streaming had in the process. However, the streaming as a exposer and agent of (im)mobility cannot be separated from other materialities involved the process and therefore we are also scrutinising what kind were the material aspects of the places people were living in, the recourses of their bodies, and how these material aspects enabled or blocked their movement.

With this, we first want to contribute to the discussion of how the arts enhance well-being, but not in the way the topic is generally understood in the field of social sciences. This means that instead of seeing well-being as an 'a-mobile' (Urry 2007) and coherent discourse, the focus on the (material) practices and multifaceted web of relationships between different people and spaces provides a more insightful understanding of the complexity of 'well-being.' The question of power is especially crucial here; discussing well-being is not an apolitical act; rather, it is inextricably linked to different power relations (Foucault 1989). As we will demonstrate, the study of movement and moorings during the streamed concerts will disclose the dynamics of these relations (Bærenholdt 2013; Jensen 2011). Second, we aim to reflect on and partly overcome the distinction between social sciences and humanities in the study of mobilities (Merriman and Pearce 2017) by analysing how movement was experienced during the streamed concerts. Third, we debate what kind of methodological tools the particular methodological approach - nexus analysis (Scollon and Scollon 2004) - could provide for the analysis of ethnographic data from the point of view of movement and non-movement, and with this we develop further research methodology in the study field of new mobilities (Merriman 2014).

Studying live-streamed concerts through the new mobilities paradigm

As stated earlier, we initially viewed the live stream concerts as complex social encounters that were difficult to fit into a narrow study framework. The fact that the different modes of mobilities, especially the virtual movement of a concert practice, were preconditions for these encounters 
raised our interest in the new mobility paradigm. The three main theoretical perspectives (i.e. the complexity theory, social practice theory and socio-technical transitions theory) that the new mobility paradigm develops (Sheller and Urry 2016) offer a fruitful framework to understand the multi-dimensionality of the live-streamed concerts. The complexity theory opens up for consideration the role that connections and movement play within the workings of institutions and how the change in the 'surroundings' of institutions changes their status quo (Sheller and Urry 2016). In the case studied here, the question of the regulation of institutions is especially crucial. As Jørgen Ole Bærenholdt (2013) has argued, Western societies are increasingly governed through movements and connections. By formulating the concept of 'governmobility,' which brings together the mobilities approach and the idea of governmentality from the Foucauldian tradition, he pinpoints how social relations between people and the political creation of societies are becoming increasingly assembled through the technologies of circulation and connection. Bærenholdt (2013) uses border studies as an example and argues that as well as demarcating territories, borders rule, push and regulate movement (i.e. they organise mobility through certain regularities).

These dynamics are also relevant to the case studied in this article: the principal aim of the livestream concerts was to include 'less fortunate' people and establish a new kind of connection between them and 'normal' society. The endeavour was principally orchestrated by current neoliberal cultural politics, which undermine the autonomy of art institutions by designating the arts as a service available to everyone (Rautiainen-Keskustalo 2013) and forcing actors within the art field to cross-institutional borders. However, this endeavour disclosed, in the case of live-stream concerts,the spatial formation of the terrain: There was a distance between the institutions and certain distanciation regimes (Handel 2017), which controlled the actions of individuals in the institutions (i.e. elderly care homes and a prison). This distance was generated by certain historically legitimated practices and aspects of interaction and routine; these aspects rule the time and personal space of individuals as well as their connections to the outside world. These institutions are often described as 'total institutions,' based on Erving Goffman's (1961) influential research. During the live-stream concerts, the practices of these 'total institutions,' which can be called 'moorings' (Urry 2003; cf. Adey 2006), were affiliated with the practices of the concert institution. In one sense, the concert institution might also be considered 'total,' because the subjects (i.e. the concertgoers) agree to the concert practices: An audience mostly sits still and listens to or contemplates the music. The lives and bodily properties of the audience are not expected to manifest. Rather, the audience displays their cultural taste by attending the institution (Small 1998). However, these totalising and 'moored' practices were rearticulated when the concerts were live-streamed from the one institution to another. Thus, the second theoretical perspective, which links this article to the new mobility paradigm and continues the study of power and 'governmobility' (Bærenholdt 2013), is concerned with how different practices before, during and after the concerts were experienced and lived by the individuals, and how these experiences highlighted the complex relationship between movement and non-movement (Sheller and Urry 2016).

As Ariel Handel (2017) has argued, distanciation regimes are also mediated by languages, emotions and world views. Similarly, Anne Jensen (2011, 266) has suggested that mobile experiences and the power relations they involve work not only at the level of knowledge and rationalities but are also 'embodied through emotions, ambiences and sensations.' The focus on materialities, meanings and sensations raises the question about research ontologies and whether the study is located in the field of social sciences or humanities (Merriman and Pearce 2017). Our theoretical and methodological frame of reference places a lot of emphasis on the social sciences, but the question concerning the various modes through which individuals can experience movement and mobility in 'alternative ways' is just as relevant (Merriman and Pearce 2017). The concept of 'kin-aesthetics,' introduced by Peter Merriman and Lynne Pearce (2017), is especially interesting 
because we argue that streamed concerts were lived, appreciated and choreographed in reimagined material places through the body and bodily movements - and also through the body's inability to move. Our main argument is that these specific ways of experiencing movement and mobility cannot be separated from situations where music and musical practices imply power and distanciation regimes of different kinds. By arguing in this way, we want to overcome, at least to some degree, the gap between the humanities and the social sciences in the studies of mobility and develop further the thinking of how music and other creative practices are part of our everyday life (Thulin 2017). The third theoretical perspective concerns live-streaming as an example of the current socio-technical transition - as 'niche innovation' (Merriman and Pearce 2017). For the concert organisers, streaming technology opened up a 'future landscape' in which it was possible to bring people together seamlessly; in other words, the need for innovation was fundamentally social. However, as argued earlier, streaming began to catalyse the socio-spatial differences between people and institutions, in other words, it created a particular kind of mediated community, 'a scape of movement' (Urry 2000, 74). Nevertheless, the configuration was not much debated by the parties, probably because live streaming is rarely used in this kind of context: generally, it is big stadium concerts or opera productions, which are live streamed to the high number of people on the internet. The idea that seniors and prisoner could form a virtual community was, then, exceptional.

\section{Data and methodology}

The streamed concert series was initially innovated by a managing director of the concert hall. The project received funding from the Finnish Ministry of Education and Culture, who considered it ground-breaking because of its cost-efficient method of producing cultural services. This justification was pointed by the concert hall when it promoted the project in public. During autumn 2014, four live-stream concerts were organised and broadcast once a month. They were implemented in collaboration with local municipal actors. The concert hall provided the concert and helped with establishing a free internet connection, while the institutions were responsible for the actual concert arrangements, including finding suitable rooms for the concerts and looking after the practical concert arrangements. The interaction between the concert hall and audiences in remote places was a key aspect of the concerts. Because of this, the opportunity for individuals to chat to each other was utilised in each concert.

During the meet-and-greet event before the concert and during the interlude(s), members of the audience could ask the artists questions and greet them, thus facilitating chatting and interaction. The repertoire of the concerts followed the supposed taste preferences of the audiences: light classical music was streamed to an elderly home, and the concert, which was streamed both to an elderly home and a prison was given by a very popular actor-singer, who is well known of his heartfelt lyrics. There were from 15 to 40 participants at each concert.

Due to the experimental nature of the project, the organisers requested collaboration from Tampere University to obtain information about the functionality of the concept, the realisations of the concerts and their potential impact. The organising body naturally expected more practical knowledge and results to be produced, but they were also open to more analytical approaches. A group of four master's students studying cultural musicology, led by their professor and a senior lecturer in social psychology, studied the implementation of the concerts using an ethnographic approach (see Rautiainen-Keskustalo et al. 2014). During the process, the group conducted about 30 interviews and observed all of the concerts, from the planning sessions to their realisation. In this article, we focus on two concerts: one that was live-streamed to an elderly home and one that 
was live-streamed to both an elderly home and a prison. We use the interviews of the organizing body, the field diaries, the chat messages and the interviews of residents and a promotional video produced by the hall during the pilot (2).

The research data was collected following the principles of multi-sited ethnographic research (Marcus 1995). This meant that we were conducting fieldwork in more than one geographical location. Because our aim was to study various encounters between the 'arts' and 'care,' we followed planning meetings in the concert hall and other spaces, interviewed the people living and working in them, participated in the concert and generally 'hung around' the project in different places. We also followed the public discussion and the promotional material that was published during the project. Because of this research setting, we chose the nexus analysis method (Scollon and Scollon 2004, 2007), which is used to study technology-mediated communication.

Nexus analysis focuses on the complex relationships between discourse and action by analysing social actions as intersections of three main components - namely, historical bodies, interaction orders and discourses in place. The concept of 'historical body' refers to the history of personal experience that is 'inscribed' into the body. It includes participants' social identities, their roles within the action and the material properties of the body. The term 'interaction order' refers to the different social arrangements of social interaction. The term 'discourses in place' concerns wider and often unsynchronised (both material and ideological) discourses that are present in the action. (Scollon and Scollon 2004.) When analysing the data, we soon identified many complexities that the grass roots encounters between different parties highlighted. We studied encounters in particular 'places,' but the importance of the connections between institutions and the movement and the nonmovement, both real and imaginary, of people and practices (Salazar, Elliot, and Norum 2017) insisted on turning our attention to the study of mobilities. The nexus analysis does not acknowledge movement as a specific areaof focus, although it aims to capture the histories and dynamics of social relationships in different infrastructures, employing, for example, the concept of ecosystem (Scollon and Scollon 2004). It can be argued that while in the nexus analysis, the nexus of practice is a momentary freeze-frame of otherwise mobile components - people, interaction, and discourses, the new mobility paradigm (Sheller and Urry 2016; Sheller 2011) 'looks beyond' the nexuses by understanding the constitutive role of movement in social practices. The difference between the concepts of 'nexus' and 'node' - the latter being one of the main concepts used to describe the nature of social action in the field of mobility studies (Hannam, Sheller, and Urry 2006) - illustrates this. While a 'nexus' carries more or less static ideas of social practices, a 'node' focuses on the flow of materiality, meanings, competences and the interrelation of places and spaces when studying social practices. Furthermore, although Scollon and Scollon (2004) discuss 'semiotic resources' - which include material aspects of interaction and communication - in practice, the nexus analysis often prioritises the study of verbal communication (i.e. the use of language)(2)"

In the following analysis, we maintain the three concepts of nexus analysis, but we look at them through the lens of the new mobility paradigm (Sheller and Urry 2016). This is because we argue that regardless of the epistemological differences the concepts of nexus analysis are beneficial in the study of rich ethnographic data because they indicate the key analytical categories. However, the concepts of nexus analysis are 'mobilised' and defined in a slightly new way, i.e. they are considered from the point of view how they disclose 'various moves', which 'make social and material realities' (Büscher, Urry, and Witchger 2011, 2). We follow Wood, Smith, and Hall (2016, 141) who have argued that 'space' and 'place' are the key concepts to understand, for example, the mobile nature of many work practices in technology-intensive societies. Firstly, in 'spaces' we include what is in nexus analysis called 'discourses in place'. We understand that discourses and practises define material and ideological 'spaces.' Secondly, what is called in nexus analysis as 
'interaction orders' are here understood as the orders that are realised in interaction and that define material and ideological 'places.' As Wood, Smith, and Hall $(2016,141)$ have argued, 'space' and 'place' are the key concepts to understand, for example, the mobile nature of many work practices in technology-intensive societies. When work moves, it crosses places, which are 'embodied and experienced,' and spaces, which are 'geographically defined' (Wood, Smith, and Hall 2016, 141). Similar dynamics concern the livestreamed concerts: During the design and implementation of the shows, the institutions that were involved were 'embodied and experienced' and 'geographically defined' in different ways by different actors. These experiences and definitions involved the issues of distance (Handel 2017) and the movement and non-movement of rules, practices, societal stigmas and materialities (4).

Thirdly, when examining the historical body from the perspective of mobilities, individual histories and movements between spaces and places come under investigation. The concerts often highlighted the prison inmates' or elderly peoples' lives before and outside the institution, if they had been, for example, active concertgoers. At the same time, the fact that their bodies were 'held in place' (i.e. rendered immobile) (Büscher, Urry, and Witchger 2011, 3) became apparent. The study of bodily histories also enables an examination of how movement and non-movement is lived and experienced in alternative ways through emotions, ambiences and sensations; i.e. through kin-aesthetics (Jensen 2011; Merriman and Pearce 2017).

In the following, we apply the concepts discussed above to the three datasets. First, we will analyse how the concerts were justified from the point of view of the organisers in terms of how the idea for them came into being and how the space and place of individuals and institutions were discussed. Second, we will examine how the concerts became a node, where questions about space and place were negotiated and experienced during the concerts among the residents of elderly homes and a prison. Third, we will discuss how the nodes constituted by the concerts generally opened up the everyday life of inmates/residents and their experiences about their position: we focus on what kind of juxtaposition was raised between institutions, which held them 'in place' and how concerts, in one hand, highlighted the body histories of the seniors and inmates, but on the other, afforded to them, in principle at least, new kind of movement.

The justification of concerts: out of institutional frames?

The idea behind the streamed concerts came from the managing director of the concert hall. She had gotten the idea from her mother, who regretted how she, as a former active concertgoer, could no longer attend concerts as she became older and more physically challenged. Artists visiting an elderly care home were 'pretty good' an option for her, but a concert in a concert hall was, for her, the 'only way to get musical experiences of high quality' (A1). Thus, through personal experiences, the director highlighted the 'aura' of the arts and the special role of art institutions in mediating this aura. This idea has deep roots in cultural modernity: the arts have been often considered a sub-system, a distinct space that has a relative autonomy and its own specific functional structure (e.g. Sevänen 2008). It has contained views about the special, even mythic, position of the artist, the special aesthetic codes (i.e. taste) and the struggle for domination of the particular social field, as Pierre Bourdieu (1984) has stated. Although these views have been challenged by many postmodern, late modern and neo-liberal veins, the discourse still has much influence today. In the interview with the managing director, the need to leave the traditional space of the art institution arose in two separate discourses concerning social impact and the economic viability of activities of the hall. Highlighting the societal impact of the project was the most important aspect for the manager. In this regard, the main incentive for her was the Act on 
Supporting the Functional Capacity of the Ageing Population and on Social and Health Care Services for Older nPeople, from the Ministry of Social Affairs and Health, which came into effect in Finland in July 2013 (Ministry of Social Affairs and Health 2012). The purpose of the act was to ensure that older people could obtain individual care services on an equal basis, according to their needs. The act also emphasised the quality of services and accessibility for all citizens. One of the services specified in the act was cultural services.

The act can be understood in terms of governmobility (Bærenholdt 2013); it challenged the concert hall to 'move' from its traditional space by creating a claim of social responsibility for the business. The underlying issue of the claim is the neo-liberal climate, which has increasingly challenged the autonomy of art institutions. In many European countries, public funding for the arts is in crisis, and cultural policies follow market-based policies (Menger 2010). The trend has been that the financial responsibility of the arts has shifted from the state to the third sector and private sponsors. The arts are seen as a 'strategic national resource' (Zeilig, Killick, and Fox 2014, 11), but where the resources are located, and how and by whom they are defined and used are questions that exceed institutional boundaries. Consequently, within the arena of cultural politics, the tendency in many European countries is to emphasise networks and platforms.

However, the managing director did not view the external pressures of the act as negative; rather, she saw that the act gave her ethical justification for the concerts. At the same time, market reasoning found a foothold in her talk. She said that a concert hall is 'like a factory' and that the pilot project was a way to implement the strategy of the concert hall: to make its utilisation rate as high as possible, reach as wide a variety of customers as possible and support local economic development. In brief, streamed concerts were only one component of the concert hall's brand. This viewpoint is not unique and perhaps not even surprising. The director highlighted the market imperatives, as is usual for anyone in her type of position in the creative industry (e.g. Lee 2016). It can be argued there was mobility/moorings dialectic (Urry 2003, 126) in the talk of managing director. On the one hand, she had to prove that the hall was simultaneously both committed to autonomous art, but on the other, she wanted to respond to demands coming from the outside and saw them as ethically justified. However, the primary goal was a profitable economic activity. Hence, it is possible to claim the discourse of inclusion promoted by the hall implemented the idea of 'policy of de-politicisation' (Lee 2016) in a similar way to what creative industry discourse does; in the discourse, art is portrayed in principle as an autonomous, positive, and value-neutral practice, and placed beyond political, economic and cultural tensions. De-politicisation was, then, the issue, which marked mobility/moorings dialectic; concerts 'moved', but there was not much consideration about the spaces where they were moving to the managing director did not ponder how the streamed concerts helped the situations of those who were 'less fortunate'. She said that the main goal of the concerts was to promote the fun of the arts, their importance and how the concerts create 'breaks' in harsh everyday life (A1). For her, streaming accomplished this almost automatically by making residents and inmates audiences of the concerts. Thus, the policy of depoliticisation was also an example of the prevalent distanciation regime (Handel 2017). This, however, was not voiced.

Among concert organisers, producers and audio-visual technicians, the distance between the concert hall and the different audiences was pondered more closely. Many of the workers said they felt sympathy for 'the guys in prison' or for elderly people 'who just sit in the lobby,' and they were happy that they 'could do something for it' (A2). One of the producers even explicitly questioned the position of the autonomous art institution by describing it as rigid and old-fashioned. They thought that the concert hall should, first of all, reconsider its role as a social institution (Teikari 2016). This straightforward view of the social-spatial power differences between the concert hall and the world 'outside' of it was unique during the process. The producer wanted to mobilise the art 
institution, but it was the actual realisation that led to the question of how multifaceted the issue of powergeometrics was between the concert hall and the audiences.

\section{Between art and care: a streamed concert as a node}

The actual realisation of the concerts was more difficult than expected; many challenges characterized the process by which concerts become 'nodes' (Hannam, Sheller, and Urry 2006, $12-$ 13). Above all, these challenged were tied to the questions what kind of places (Wood, Smith, and Hall 2016) care institutions and a prison were; first, how everyday life was organised in these 'material' places, and secondly, how interaction between people was understood and regulated. For example, the concerts usually began at 7:00 p.m., which, for the residents of the elderly care homes, was almost bedtime. In addition, the nurses' personal interest had an effect on how the concerts were organised and how the residents were involved in the concert. Those who were culturally oriented were ready to help as much as possible in the concert arrangements, while others considered the concerts an unnecessary duty in their busy working day (Rautiainen-Keskustalo et al. 2014; Colliander 2014). In essence, 'culture' was not a field that was considered to be within the realm of a nurse's daily work. In the prison, the idea that everyone could participate in the concerts was unrealistic: depending on their sentences, prison inmates had different rights in terms of moving around and communicating. This caused the prison staff to anticipate possible risks and call for special arrangements during the concerts.

Despite these challenges, the aim of the organisers was to create an authentic experience, and the personnel of the institutions, almost without exception, agreed enthusiastically with this demand. The viewing room, which was often a dining room or equivalent, was arranged in the form of a concert hall, although this process also faced obstacles. The facilities of the care homes for elderly people and those of the prison were largely unsuitable, being either too small or too large. In addition, the care homes did not have proper sound systems, and internet access was often interrupted during the concerts. In some cases, like in the prison, a special broadband connection was created, because the existing connection could not be used for security reasons. Thus, in terms of sound quality and space design, it was difficult to guarantee similar conditions. However, during the realisation of the concerts, all of these obstacles seemed to fade away. All parties shared the view that the concerts become a shared experience. Preparing for a concert dressing, coming to the 'concert venue' and waiting for the concert to begin - was something exceptional compared to the everyday activities of the institutions. The places where they were living, which were normally experienced in a 'fixed' way, were now 'moving around' at an imaginative level (see Büscher, Urry, and Witchger 2011). The social life of the institutions was reorchestrated, and new connections were forged. In addition to daily practices, the movement of the concerts from the concert hall to the institutions rearranged and mobilised the social relationships between the individuals inside the institutions. The rules that generally determined interaction did not, at least temporarily, bind action. One resident of a care home paid attention to how the staff had specially prepared for the concert and 'how the beautiful hair of the director was untied' (A3). In other words, the managing director of the care home exceeded her working role. In the prison, the prison inmates baked pies for the concert with a staff member. In addition, one of the inmates wondered aloud during the special concert promo why he, a prisoner, was asked his opinions about the concert arrangements - nobody had asked his opinions before (A4). The organisers recognised this with satisfaction and soon began to lobby for more concerts by emphasising how they led to an increased sense of community. They made a promo video during the pilot. In this pilot, two residents of the service centre spoke about their experiences: 
There was jewellery and lipstick, we were so, so . . f focused and listened really intently. Of course, we wanted

to dress up a little, so that we wouldn't look like just straight out of the kitchen. Kallu [pointing to the person in the interview], you also noticed that women were pretty and had their best dress on. I am not kidding! Right after the concert, it felt like we had been in some fancy place, even though it was just the cafeteria. But it gave us that kind of feeling. Even though we are old, we are still humans. It felt like we are still appreciated! We got a feeling that we are not just 'in the way'. (MUKANA [Event Online] Brings Event Close to You, 2014)3

This example illustrates well how elderly people observed, even in an enthusiastic manner, the node, which was generated by the live streamed concert: they were dressed well and listening intensively as if inside a concert hall, yet being in a cafeteria. In other words, the concerts were experienced materially through the practices of listening, and generally, acting like the person was at a concert. This particular experience of concert situation together with notions about the new kind of 'mobilisation' of the daily practices, and relationships can be understood in terms of 'kinaesthetics' (Merriman and Pearce 2017, 498). The concerts trespassed the moored practices of the institutions even before implementation. For instance, the observations of the seniors of how the chairs and tables were re-organised when they entered to a cafeteria which was turned into a concert venue, and how people in there were acting not-so normative ways, illustrate this. The change also evoked the body histories of the residents. The issue came up, for instance, in the care homes when seniors who could not hear correctly and who had been active concertgoers before, said that participation in a streamed concert was important for them; it revived meaningful memories attached to the practices when they had no physical or other obstacles to participate in the concerts. In other words, concerts brought back something from their 'normal' life they had lived before. These moments afforded, then, embodied and sensed experiences both of the past and present, which one resident called 'dignity', i.e. the question was more than that just the change of routines (ibid. 499).

In a prison, we observed similar kind of moments of 'kin-aesthetics' when prisoners responded positively to special arrangements, which changed their everyday routines before and during the concerts. However, their action was specially framed by the institution: the fundamental question was what kind of power relations determined inmates' space and their connections to society.

Negotiating inclusion: place, space and power

As we mentioned earlier, for the managing director, the inclusion of individuals was achieved when residents in different institutions came together with 'ordinary' people through live-streaming. In other words, live-streaming was, to her, a way of creating a shared space. In a sense, this goal was achieved, but as shown above, the meaningful aspects of the concerts arose primarily from the material and social circumstances of the institutions. The spatial relations between the institutions and society 'outside' were far more complex issues. This is illustrated in the comment of one senior, who said that it was important for them that someone saw them as worthy of this service. In everyday life, they often felt that they were 'in the way' and cause expenses to society.

The practical implementation of the concerts also illustrated the complexity of the idea of the shared space. For example, it is difficult to say how the audience in the concert hall recognised the existence of the remote audiences: The audience was informed of the live-streaming by the host, and some artists sent greetings via chat to remote audiences during the concerts, but the people in the concert hall did not see them. We had the idea of interviewing the audience members about their opinions concerning the remote concerts, but they were so focused on their own concert experience that it was awkward to bring up the topic and engage in discussions. 
The discussion about the shared space that the concerts afforded was problematic, especially when a prison came into the picture. In this respect, the most unique incident happened in the concert that was streamed both to the prison and the elderly care home. During the concert, the residents of the elderly care home began to send online messages to the prison. This was not exactly planned: The online connection was intended to serve as a connection between the concert hall and the institutions. However, the elderly residents began to send greetings to the prison and wanted to know how things were there:

- Greetings to Kylmäkoski [the prison] from Meri, 70 years. We will meet at KRIS4.

- Greetings from Lea to Kylmäkoski!

- We have Pappilanpuisto [the elderly care home] coffee and mince pies. What do you have there?

- There are very good dishes here. Coffee, Sachertorte et al. (A6)

This incident, which placed two different audiences side by side, raised the question of the spatial distance between said audiences. As mentioned previously, the concerts raised positive responses in the prison in a way that was similar to the elderly care homes, but principally, the node generated by the concert was completely different in structure. Negotiations over rules and regulations took place in carceral dispositif (Mincke and Lemmone 2014), where the exclusion was not, as in the case of the elderly, a socially recognised problem, but a principal course of action of the institution. The positive astonishment of an inmate replying to the question concerning the practical arrangements of the concerts illustrates this well. Normally, the inmates applied norms set by others (Mincke and Lemmone 2014). However, the next question, which was regularly raised, was 'Do we deserve this because we were serving sentences, have we screwed things up?' Thus, despite all efforts to change everyday life in prison, even if just for a moment, this particular question showed how loyalty to the institution and submission to power lay within the prison inmates (e.g. Scott 2010). Consequently, the connection afforded by the concerts to the world outside was particularly problematic: prisoners felt how the institution made them immobile, but they were not able to identify with the society outside and its appreciated practices like highstandard concerts. They said, for example, that 'culture' was something they wanted to stand out, and their attitudes towards the concert were defiant. Some of them emphasised how the concert was the first one at which they were sober (A7). In other words, there were not many possibilities for prison inmates to overcome the complex distanciation regimes set by society (Handel 2017). Thus, it was difficult for them to obtain a sense of team spirit with the elderly.

Nor was the sense of community commonly shared in the elderly care homes. For many, isolation and solitude were essential and fundamental experiences. This was not an easy problem to resolve. These feelings, which a resident of a care home had when she described her daily life, were shared by many:

You know, my day is, like, I sit on my bed, I go to the fridge, I sit on my bed and watch, I go to the loo, sit on the bed and watch. I don't have anything to do. (A7)

The problems of the physical body became a critical factor through which the personal meanings of the concerts were negotiated in the elderly care home. The fading strength and capability of the senior led to a sense of exclusion in two ways. First, many highlighted the institutional stigma of the elderly care home as a 'waiting room of death':

Some artists who come here often act as if we were dying. So serious and so sad. Or they act as if we were braindead. Yes, we will regress to childhood, but most of us understand what is going outside. They don't need to come here and play as if we were dim-witted. (A7) 
The interviewee wanted to highlight that visitors could not understand the life-world of the elderly, where they had to adjust their preferences and everyday lives according to their physical conditions. However, this did not mean they had no opinions or were unwilling to fulfil their needs in the ways their bodies allowed them. This issue proved to be a difficult one to notice, even for the research group. The interviews made during the pilot began with the concept of taste, following the theory distinction by Pierre Bourdieu (1984). The research group expected the residents to talk about their likes and dislikes, specifically in relation to concerts. In other words, we had a presumption that concerts were experienced first-hand through these preferences (e.g. Prior 2016). Some of the residents did talk about their taste preferences, but not all. For many, the physical hurdles they endured and the effect of these hurdles on their everyday lives framed their discussion of their preferences. This is exemplified in the following extract, where the interviewer repeatedly asked questions about the musical preferences and listening habits of the interviewee. The interviewee, in turn, emphasised her hearing problems, which determined her taste preferences:

Q: Do you ever listen to music, radio, LPs?

A: You know, I have a hearing aid. I have earphones, but I don't bother to find them and use them. So, I don't listen to music so much. And I don't want to have the TV loud. Here [in the care home], live music concerts are organised, and I often come here. But in my own room, I just sit in silence quite often. You miss a lot, when you lose your sense of hearing. You don't hear music perfectly.

Q: Have you watched concerts on TV?

A: Yes, I have watched and listened. 'Light music' concerts of different artists. In the Independence Day celebration, I was listening to Vesa-Matti Loiri. I put more volume on [sic]. Q: What kind of concerts do you like, 'light music'?

A: It depends on the concerts. I don't care so much for symphonies. I don't listen. I must say that if music was number one before, now the books are in the first place, because of the circumstances. There is no enjoyment, if you are not hearing well (A7).

The excerpt raises the concept of kin-aesthetics discussed earlier in this article but from a different angle. If, then, the re-lived concert practices generated meaningful moments for seniors, the other side of the coin was that these alternative ways to experience concerts were often also inevitable: it was what the body was capable of. This observation leads to ponder if the Western idea of cultural taste is eventually discriminating because it often ignores the fact that people's (bodily) resources are different and change during the life cycle and there is a great variety of ways, which often exceed the conventional cultural categories, how people experience everyday life and, for example, art."

However, during the pilot, there was not much discussion about the possible obstacles in the physical condition of the seniors, rather, they were categorised as just an 'audience'.

The examples above highlight how the streamed concerts disclosed the complex relationships between spaces, places and the body (c.f. Wood, Smith, and Hall 2016, 141); the concerts allowed room to experience places (an elderly home, a prison) in new ways, but as we have shown, all experiences were different and uneven. These differences, in turn, tell about distance and the legitimation of power relations; about the nature of geographically, historically and materially formulated spaces between elderly people, prisoners, and 'ordinary' people. Ultimately, these spaces were impossible to transcend.

In the analysis, we have focused on the 'audiences,' but a similar kind of dynamics also concerned the staff. There were staff members who were culturally oriented and saw the concerts as a chance to regenerate the structures of everyday life. However, the fact that they were isolated to a specific and materially and ideologically isolated space restricted their actions. However, it is also possible to argue that an aspiration to cross borders was not on everyone's agenda. 


\section{Conclusions}

In this article, we have studied how the ideological discourses and practical actions that aimto increase well-being through art-based approaches can be understood from the perspectives of mobilities and immobilities (Urry 2000, 2007; Büscher, Sheller, and Tyfield 2016; Sheller and Urry 2016). In the case analysed, real-time access in the form of live-streaming resulted in complex relational dynamics between individuals and institutions. However, the idea of 'movement' was not explicitly highlighted during the process. Rather, the pilot was perceived as if the concerts were simply carried over from place to place; how the movement came about was not recognised. From that perspective, our aimhas been to 'draw out' what was not seen: we explored how the flows of the different scales of the network developed and evolved. Thereby our aim has been to think 'social as mobility' (Urry 2000, 2)

Methodologically, we followed the approach of multi-sided ethnographic research, which often serves as the starting point also for studies of mobilities, albeit the methodological choices within this field vary significantly and have undergone detailed discussions (see Büscher, Urry, and Witchger 2011; Merriman 2014; Salazar, Elliot, and Norum 2017). Our approach can be associated with anthropological studies that focus on mobilities: we have aimed to 're-examine the ontological status of local' and contextualise 'sites within networks and flows across diffuse time-spaces' (Salazar, Elliot, and Norum 2017, 9). To achieve this goal, we have utilised the three concepts of the nexus analysis (i.e. discourses in place, interaction order and historical body). These concepts point the key encounters taking place between different people and institutions and how these encounters are conducted under specific semiotic-material resources (Scollon and Scollon 2004). However, we 'mobilised' the concepts by looking 'beyond' them and asked how the encounters highlighted movement and non-movement of different scale (societal, social and material/bodyrelated). By doing this, the nexus of nexus analysis was renamed as a node. The 'mobilisation' of these concepts has also meant that we have specially reinforced the analysis of the material aspects of the encounters in terms of how they condition movement and non-movement. We argue that the concepts of nexus analysis used in this particular way is beneficial for the investigations of complex societal phenomena and current political flows, where the questions of mobility and immobility imply multifaceted power relations, but are often somehow 'out of sight'.

With the help of slightly revised concepts, we identified the different power relations the network mediated, which can be understood in the terms of governmobility (Bærenholdt 2013). The main motivation for the streamed concerts was the idea of the social responsibility of a business (Lee 2016), which urged an art institution to step out from its traditional sphere. The concert hall, in turn, wanted to show its ability to answer current demands, but at the same time, it followed the logics of the business: culture for all at a low cost.

While these contradictory discourses demonstrate how an art institution is governed through mobility by a neo-liberal cultural policy, the streamed concerts also disclosed many other power relations and ways of experiencing power in the nodes constituted by the concerts (Jensen 2011). The differences that arose during the concerts, in terms of the participants' experiences of place and space, illustrate this well. For the organisers, the concerts were 'positive,' 'fun' and a value neutral terrain and the political aspects of culture (Lee 2016) were swept aside. For the elderly residents and the prison inmates, the concerts were experienced as positive, but mainly because they provided an immediate opportunity to experience movement. This opportunity presented a new kind of agency and empowerment (see Merriman and Pearce 2017) through material and body-related concert practices in environments that were generally ruled by 'moored practices.' 
However, it was almost impossible to overcome differences between spaces in terms of the histories of the institutions and the elderly residents'/prison inmates' roles on the margins of society. In other words, the 'movement' of a concert institution revealed what did not move and what was deeply political (Sheller 2011; Hannam, Sheller, and Urry 2006). The observations we made concerning prison inmates and the elderly mirror this well. The feeling of being an outsider as well as feelings of guilt and inadequacy in the eyes of society became apparent, both among the prison inmates and the elderly. In the case of the prison inmates, these feelings were aroused from the history of the institution (Goffman 1961) in question. In the elderly care homes, the feeling of being an outsider arose from the inevitable loss of physical abilities. This is an issue that seems to be slightly ‘taboo' in public discourses on ageing (Jolanki 2009; Katz 2000).

It is important to note that live-streaming was the starting point of everything. As de-materiali sed actor, it orchestrated the formation of the assembly, a scape of movement and offered a novel 'future landscape' (Sheller and Urry 2016) for organisers to overcome societal inequalities by means of culture. However, technology did not redeem the expectations placed on it. Live-streamed concerts were a short-lived experiment, and the concert hall later withdrew from the project because the organising of the concerts was considered too time-consuming, and there was not enough demand. This was not a surprise: The social terrain for this technological innovation was far too complex to evolve into a 'regime' (Sheller and Urry 2016).

How then can our perspective be set to the paradigm of new mobilities, and how is the focus of this article, the 'arts as well-being,' a relevant theme from this angle? Firstly, with our analysis, we wanted to bring together the 'social' concerns of sociology (e.g. inequality, power and hierarchies) with various geographical aspects (e.g. institutions as territories and distance(s)) (c.f. Sheller 2011). This combination enabled us to debate how the 'arts as well-being' is located within the field of social struggles. As our analysis has demonstrated, social divisions and distinctions have a long, often institutional history, but when they encounter with the current demands of neo-liberal networked economies, the result is complex mobility/moorings constellations (Urry 2003). Maybe one of the most eye-opening examples in this sense was when we were talking about the organising of a concert in a brand-new cafeteria of a service centre. The cafeteria was virtually empty because the prices of the food were too high for the majority of the seniors. These kinds of preconditions set by current market-based social policies were not a very good starting point to plan 'a gig' meant to be inclusive for all.

Secondly, our aim was to argue that these social and economic aspects that define the arts as wellbeing through mobility cannot be separated from the perspectives of the kin-aesthetics of movement (Merriman and Pearce 2017; Sheller 2011) that are lived through socio-material practices. This is also where the distinction between social sciences and humanities is neither justifiable nor appropriate. As our analysis has shown, these embodied practices create knowledge and crucial experiences of places and spaces, but in everyday life, these aspects are rarely recognised. Thus, we argue that the ethnographic approach for the study of ideologies and actions through complex constellations of movement and stillness gives in-depth to perspectives to the worlds-in-making in the era of flows and networks.

\section{Notes}

1. The study field of the 'arts as well-being' is vast, and it is not possible to discuss it in detail here. There are many variations in terms of how the topic is located in the political agenda of different European countries (e.g. Alasuutari 2017). However, generally speaking, one of the most debated issues has been how to measure the evidence of art-based interventions (e.g. Daykin et al. 2017). 
2. In the project, we followed the ethical guidelines set by the Finnish Advisory Board on Research Integrity

(2013). Every person who participated in interviews signed an informed consent form, and they were reminded that participation was voluntary and they had the right to withdraw from the study at any stage. In reporting the results, as in this article, the group endeavoured to protect the identities of the participants by anonymizing any details that would result in the recognition of individual participants, such as names and other personal information. All of the research material is preserved by the research team.

3. This video is freely available on the internet. The research material obtained from the mental hospital is not used in this article because the research group had limited permission to gather data due to hospital privacy policies.

4. Meri refers here to K.R.I.S, a Swedish-born organization that also operates in Finland and helps former prisoners adapt to the society after a prison period.

\section{Acknowledgements}

Thanks to the two anonymous referees, whose comments on previous version of this paper were instrumental in helping to improve it. We are also grateful to the research team examining the remote concert together with us - various discussions during and after the project planted the seed of an idea for this paper.

Disclosure statement

No potential conflict of interest was reported by the authors.

ORCID

Tarja Rautiainen-Keskustalo http://orcid.org/0000-0003-3395-7127

\section{References}

Adey, P. 2006. "If Mobility Is Everything Then It Is Nothing: Towards a Relational Politics of (Im)Mobilities." Mobilities 1 (1): 75-94. doi:10.1080/17450100500489080.

Alasuutari, P. 2017. "Authority in the Rhetoric of Persuasion: The Global Spread and Domestication in Finland of the

Concept of Wellbeing." [Määräysvalta vakuuttelun retoriikassa. Koetun hyvinvoinnin käsitteen leviäminen ja kotoistuminen suomeen.] Sosiologia 54 (3): 253-272.

Bærenholdt, J. O. 2013. “Governmobility: The Powers of Mobility.” Mobilities 8 (1): 20-34. doi:10.1080/17450101.2012.747754.

Bourdieu, P. 1984. Distinction: A Social Critique of the Judgement of Taste. London: Routledge \& Kegan Paul.

Büscher, M., M. Sheller, and D. Tyfield. 2016. “Mobility Intersections: Social Research, Social Futures.” Mobilities 11 (4): 485-497. doi:10.1080/17450101.2016.1211818.

Büscher, M., J. Urry, and K. Witchger. 2011. Mobile Methods. Abingdon: Routledge.

Clements, P. 2011. "The Recuperation of Participatory Arts Practices." International Journal of Art \& Design Education 30

(1): 18-30. doi:10.1111/j.1476-8070.2011.01678.x.

Clift, S. 2012. "Creative Arts as a Public Health Resource: Moving from Practice-Based Research to Evidence-Based

Research." Perspectives in Public Health 132 (3): 120-127. doi:10.1177/1757913912442269.

Colliander, M. 2014. "Encounters between Art and Care. The Agency of the Personnel in the Pilots of Etäevent

Concerts." [Kulttuuri ja hoiva kohtaavat. Etäkohteiden henkilökunnan toimijuus Etäevent-konserttien pilotoinnissa.].

Master's thesis, University of Tampere.

Daykin, N., L. Mansfield, A. Payne, T. Kay, C. Meads, G. D’Innocenzo, A. Burnett, et al. 2017. “What Works for Wellbeing in Culture and Sport? Report of a DELPHI Process to Support Coproduction and Establish Principles and Parameters of an Evidence Review." Perspectives in Public Health 137 (5): 281-288. DOI:10.1177/1757913916674038.

Foucault, M. 1989. The Order of Things: An Archaeology of the Human Sciences. Reprint. London: Routledge.

Goffman, E. 1961. Asylums: Essays on the Social Situation of Mental Patients and Other Inmates. New York: Anchor Books.

Handel, A. 2017. “Distance Matters: Mobilities and the Politics of Distance." Mobilities 13 (4): 1-15. doi:10.1080/

17450101.2017.1394681.

Hannam, K., M. Sheller, and J. Urry. 2006. "Mobilities, Immobilities, and Moorings." Mobilities 1 (1): 1-22. doi:10.1080/

17450100500489189.

Jensen, A. 2011. "Mobility, Space and Power. On the Multiplicities of Seeing Mobility." Mobilities 6 (2): 255-271.

doi:10.1080/17450101.2011.552903.

Jolanki, O. 2009. "Agency in Talk about Old Age and Health." Journal of Aging Studies 23 (4): 215-226. doi:10.1016/j.

jaging.2007.12.020.

Katz, S. 2000. "Busy Bodies: Activity, Aging, and the Management of Everyday Life." Journal of Aging Studies 14 (2):

135-152. doi:10.1016/S0890-4065(00)80008-0.

Lee, H. K. 2016. "Politics of the Creative Industries Discourse and Its Variants." International Journal of Cultural Policy 22

(3): 438-455. doi:10.1080/10286632.2014.991783. 
Marcus, G. E. 1995. "Ethnography In/Of the World System. The Emergence of Multi-Sited Ethnography." Annual Review of Anthropology 24: 95-97. doi:10.1146/annurev.an.24.100195.000523.

Menger, P. M. 2010. "Cultural Policies in Europe: From a State to a City-Centered Perspective on Cultural Generativity." GRIPS Discussion Paper 1028. Accessed 10 June 2018. http://www3.grips.ac.jp/ pinc/data/10-28.pdf

Merriman, P. 2014. "Rethinking Mobile Methods." Mobilites 9 (2): 167-187. doi:10.1080/17450101.2013.784540.

Merriman, P., and L. Pearce. 2017. "Mobility and the Humanities.” Mobilities 12 (4): 493-508. doi:10.1080/

17450101.2017.1330853.

Mincke, C., and A. Lemmone. 2014. "Prison and (Im)Mobility. What about Foucault?" Mobilities 9 (4): 528-549.

doi:10.1080/17450101.2014.961258.

Ministry of Social Affairs and Health. 2012. Press release. Accessed 3 March 2018. http://stm.fi/en/artikkeli/-/asset_ publisher/lagen-om-aldreservice-tryggar-hogkvalitativa-tjanster-for-aldre-i-hela-landet

Prior, N. 2016. "Bourdieu and the Sociology of Music Consumption: A Critical Assessment of Recent Developments." Sociology Compass 7 (3): 181-193. doi:10.1111/soc4.12020.

Rautiainen-Keskustalo, T. 2013. "Art as a Service and the 'Surplus Value of Art' - About the Value of Music in the Age of Competition Capitalism." [Taide palveluna ja taide arvonluojana - musiikin arvosta ja lisäarvosta kilpailukapitalismissa.] In Tehtävä kulttuurille [A Mission to Culture], edited by M. Lehtonen, K. Valaskivi, and H. Kuusela, 71-94. Tampere: Vastapaino.

Rautiainen-Keskustalo, T., S. Raudaskoski, M. Colliander, A. Rantanen, A. Pimiä, and A. Teikari. 2014. "Multifaceted Remote Concert. Nexus Analysis as a Research Method of Musical Practice." [Moniaineksinen etäkonsertti.

Neksusanalyysi Musiikillisen toiminnan tutkimusmetodina.] Musiikki: Suomen musiikkitieteellisen seuran julkaisu 44 (1): 6-28. http://elektra.helsinki.fi/se/m/0355-1059/44/1-2/neksusan.pdf

Salazar, N. B., A. Elliot, and R. Norum. 2017. Studying Mobilities: Theoretical Notes and Methodological Queries. Methodologies of Mobility: Ethnography and Experiment. New York and Oxford: Berghahn.

Scollon, R., and S. W. Scollon. 2004. Nexus Analysis: Discourse and the Emerging Internet. London: Routledge.

Scollon, R., and S. W. Scollon. 2007. "Nexus Analysis: Refocusing Ethnography on Action." Journal of Sociolinguistics 11 (5): 608-625. doi:10.1111/j.1467-9841.2007.00342.x.

Scott, S. 2010. "Revisiting the Total Institution: Performative Regulation in the Reinventive Institution." Sociology 44 (2): 213-231. doi:10.1177/0038038509357198.

Sevänen, E. 2008. The Modern and Contemporary Sphere of Art and Its Place in Societal-Cultural Reality in the Light of System-Theoretical and Systemic Sociology. Joensuu: Joensuun yliopisto, yhteiskunta- ja aluetieteiden tiedekunta. Sheller, M. 2011. "Mobility." Sociopedia.isa. Accessed 28 April 2017. http://www.sagepub.net/isa/resources/pdf/mobility Sheller, M., and J. Urry. 2016. "Mobilizing the New Mobilities Paradigm." Applied Mobilities 1 (1): 10-25. doi:10.1080/ 23800127.2016.1151216.

Small, C. 1998. Musicking: The Meanings of Performing and Listening. Hanover: University Press of New England. Teikari, A. 2016. "An Accessible Remote Concert and the New Definitions of the Concert Institution." [Saavutettava etäkonsertti ja konsertti-instituution uudet määritelmät.] Master's thesis, University of Tampere.

Thulin, S. 2017. “Listening to Mobility and Location-Based Media. Verdun Music-Route." In Envisioning Networked Urban Mobilities: Art, Performances, Impacts, edited by A. Kjærulff, S. Kesselring, P. Peters, and K. Hannam, 38-47. New York: Routledge.

Urry, J. 2000. Sociology beyond Societies: Mobilities for the Twenty-First Century. London: Routledge.

Urry, J. 2003. Global Complexity. Cambridge: Polity Press.

Urry, J. 2007. Mobilities. Cambridge: Polity Press.

Wood, L. A., R. J. Smith, and T. Hall. 2016. "Work on the Move: Editors' Introduction to the Special Issue." Applied Mobilities 2 (1): 139-146. doi:10.1080/23800127.2016.1250371.

Zeilig, H., J. Killick, and C. Fox. 2014. "The Participative Arts for People Living with Dementia: A Critical Review." International Journal of Ageing and Later Life 9 (1): 7-34. doi:10.3384/ijal.1652-8670.14238.

\section{Empirical data}

A1: Interview with managing director (25 February 2014). Interviewer: Anne Teikari.

A2: Interview with the staff members of the concert hall (8 November 2013). Interviewer: Anne Teikari.

A3: Interviews with staff members in a care home (8 November 2013). Interviewer: Marjukka Colliander.

A4: Fieldnotes, 2013-2014, by Tarja Rautiainen-Keskustalo.

A5: Fieldnotes, 2013-2014, by Tarja Rautiainen-Keskustalo.

A6: Fieldnotes, 2013-2014, by Rautiainen-Keskustalo.

A7: Interview with an elderly person (11 November 2013). Interviewer: Anna Rantanen.

Interviews and fieldnotes

Videos

MUKANA (Event Online) Tuo tapahtumat lähellesi (MUKANA [Event Online] Brings Event Close to You) (2014) Available at https://www.youtube.com/watch?v=B5BBLlokYqg 